\section{Sustainability and Well-being in Geriatrics: proposing a performance-based approach for the implementation of geriatric care activities}

\author{
Liliana Mazza, ${ }^{1}$ Riccardo Ievoli ${ }^{2}$ \\ ${ }^{1}$ U.O.C. Geriatria, Ospedale Maggiore, \\ AUSL Bologna; ${ }^{2}$ Department of \\ Economics and Management, University \\ of Ferrara, Italy
}

\begin{abstract}
The evaluation and measurement of Sustainable Development and Well-being represent a widespread emerging theme in healthcare, especially concerning, among others, the concepts of social equity and universality of health from an intergenerational perspective. To achieve such goals, Geriatrics would play a prominent role, especially considering the growing portion of the senior population in developed countries.

This work intends to explore the possibility to connect Sustainable Development Goals and dimensions of Well-being to a set of performance indicators which are representative of geriatric activities in different settings of care. To this purpose, a pattern of indicators from EmiliaRomagna Region (RER) in Italy is considered. Furthermore, a range of Transitional Care interventions is discussed and proposed in order to ameliorate (or keep stable) the performance.
\end{abstract}

\section{Introduction}

The Italian population accounts for nearly 60 million people and almost a quarter $(23 \%)$ is aged 65 or above. This portion of the population has an average life expectancy of about 20 years (women 22.4 years, men 19.3 years), making Italy the oldest country in Europe. ${ }^{1}$

Medical innovations in diagnostic technologies, timeliness of treatment and global improvement of healthcare services has undoubtedly contributed to longevity. As a counterpart, living longer frequently results in gaining multiple pathologies during the path of life, coexisting with chronic diseases and disability for decades. $^{2}$

The relevance of this topic in terms of medical, nursing and generical healthcare assistance is well-known among professionals. Seniors are commonly highly complex, vulnerable, frail patients, representing a challenge for medicine due to their heavy health and care needs. In parallel, hospital networks are experiencing a whirlwind surge of older people: according to an English study, between 1990 and 2004 accesses in Emergency Departments (ED) by patients with 70 years or above increased by $198 \%$, those by seniors with more than 90 years increased by $671 \%{ }^{3}$ Similarly, medical and surgical wards show a high rate of hospitalization for elderly patients, where length of stays depend on the complications associated with hospitalization or discharge procedures. ${ }^{4}$ The prolongation of hospital stay is more frequent, above all, in oldest-old, frail, nonautonomous patients with various comorbidities and cognitive or behavioral disturbs. Nonetheless, the amount of prolonged hospitalizations resulting from inappropriate recovery should not be neglected. ${ }^{5}$

From the point of view of the territorial districts, local primary healthcare centers represent a focal point in the management of assistance activities especially for nonself-sufficient patients, with a significant portion of activities delivered at home.

Starting from these points, two considerations arise as follows. First of all, defining the adequate setting of care for each patient at each moment of transit in the health services network emerges as a practical solution to improve the efficiency of health services themselves, while ameliorating the outcome on patients' health and quality of life. Furthermore, in a perspective of social equity, accessibility to health services must be guaranteed to seniors equally as to the whole population. ${ }^{6}$ According to this field, World Health Organization (WHO) has declared the necessity to promote Universal Health Coverage (UHC), including the full spectrum of essential, quality health services, from health promotion to prevention, treatment, rehabilitation, and palliative care. ${ }^{7}$

The aforementioned concepts are strictly adherent to the international and national frameworks for the evaluation and measurement of Well-being and Sustainable Development. In this sense, the relationships between United Nations' Sustainable Development Goals (SDGs) ${ }^{8}$ and Medicine or Healthcare ${ }^{9}$ have been investigated in some recent contributions. ${ }^{10,11}$

Nevertheless, the current Literature seems to lack concerning the role of Geriatrics in the empowerment of SDGs. Similarly, to the best of our knowledge, the
Correspondence: Liliana Mazza, U.O.C Geriatria, Ospedale Maggiore, Largo B. Nigrisoli 2, Bologna, Italy.

E-mail: 1iliana.mazza3@gmail.com

Key words: Continuity of care; transitional care; sustainability; well-being; performance.

Contributions: LM wrote the article and revised the current medical literature. RI contributed with economic definitions and revised the current literature about Sustainability and Well-being indicators.

Conflict of interests: the authors declare no potential conflict of interests.

Availability of data and materials: data and further materials can be found online, as described in References.

Ethics approval and consent to participate: not applicable.

Received for publication: 18 March 2021. Accepted for publication: 25 May 2021.

This work is licensed under a Creative Commons Attribution-NonCommercial 4.0 International License (CC BY-NC 4.0).

${ }^{\circ}$ Copyright: the Author(s), 2021

Licensee PAGEPress, Italy

Geriatric Care 2021; 7:9764

doi:10.4081/gc.2021.9764

links with other Well-being frameworks, such as the Italian 'Benessere Equo $e$ Sostenibile' (BES), have never been adequately studied.

Hence, the proposal of a connection between these frameworks and geriatric practice might be useful to identify, at first, the main dimensions (denoted as 'Goals' or 'Domains') and reference indicators which could benefit from geriatric expertise at international, national and, in particular, at a local level.

The aim of this perspective paper is to exploit the connections between Geriatrics and international and national frameworks for the measurement of Sustainable Development and Well-being. In this sense, the methodology can be divided in three sequent parts, summarized in the Logical Framework (LC) shown in Figure 1. Firstly, SDGs, BES and their related indicators implied in geriatric activities are introduced and discussed. Then, a set of performance indicators, retrieved from the performance measurement and evaluation system document of an Italian region, is also defined and described. This stage is crucial to systematize healthcare performance to sustainability. Finally, for each 
performance indicator, some innovative opportunities and practical solutions to improve healthcare services are provided.

\section{Geriatric-related goals and indicators from national and international frameworks on Sustainability and Well-being}

The first step is to study whether any goal and/or related indicators included in SDGs and BES can be connected to geriatric themes. To this purpose, the following four categories are considered to identify the outcome of interests: i) health; ii) hospital and local assistance; iii) population by 65 years or above; iv) diseases and comorbidities of geriatric interest.

On such basis, seven indicators are selected and summarized in Table 1, depicting information such as the source (SDGs or BES), the reference Goal (or domain in the BES case) and the direction (positive or negative).

Concerning SDGs, this system is the most relevant at an international level and includes 17 Goals (Figure 2) further divided into 169 targets, ${ }^{12}$ with a total of almost 300 statistical measures in the Italian version. ${ }^{13}$ All the identified indicators can be found in the 'Good Health and Well-being' Goal (n. 3), with the targets 3.8 'Achieve universal health coverage (...)' and 3.b 'Support the research and development of vaccines (...).' The former regards the availability of hospital, day-hospital and residential beds, while the latter is related to Influenza vaccination coverage. It should be noticed that only the latter indicator is directly referred to older people (65 years or above). In fact, SDGs are conceived at an international level and may not appear directly calibrated to each country's situation, even if there are some advanced experiments to measure SDGs at the territorial level. ${ }^{14,15}$

To overcome this gap, reference can be made to other systems of indicators, such as the Italian BES, developed by the National Institute of Statistics (ISTAT) and the National Council of Economy and Labor (CNEL).

The BES framework comprehends 130 indicators divided in 12 domains (Figure 3), regarding aspects such as Health, Education and Training, Social Relationships, Environments and so on. ${ }^{16}$ These indicators are also used to construct 15 composite indices at national and regional (NUTS 2 Region) level, ${ }^{17}$ but also at a local level. ${ }^{18}$
Among BES indicators, three can be linked to the geriatric concern. In 'Domain 1: Health' there are: 'Age-standardized mortality rate for dementia and nervous system diseases (65 years and over)' and 'Life expectancy without activity limitations at 65 years of age' (labelled as 1.6 and 1.7). In 'Domain 12: Quality of Services', 'Integrated home activity service for the elderly' (labelled as 12.3) is measured.

Regarding the trend of selected SDGs indicators in Italy, the situation exposes some critical issues. Comparing the last update with the previous year data, a decrease in the number of available day-hospital beds is observed, while the other indicators appear stable over time. For two over four indica-

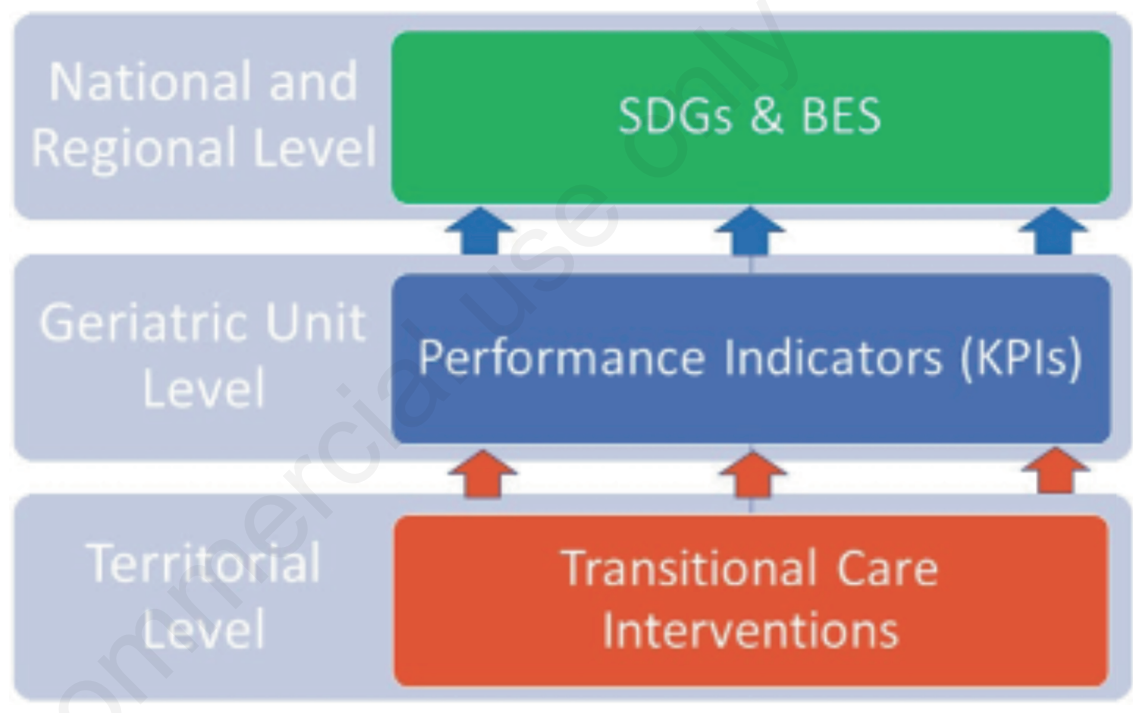

Figure 1. This Logical Framework shows the methodology adopted in this work. Hierarchically, Sustainable Development Goals (SDGs) and Benessere Equo e Sostenibile (BES) are defined prior to Key Performance Indicators (KPIs), whose improvement is related to transitional care interventions. Logically, the impact is reversal, as depicted by arrows.

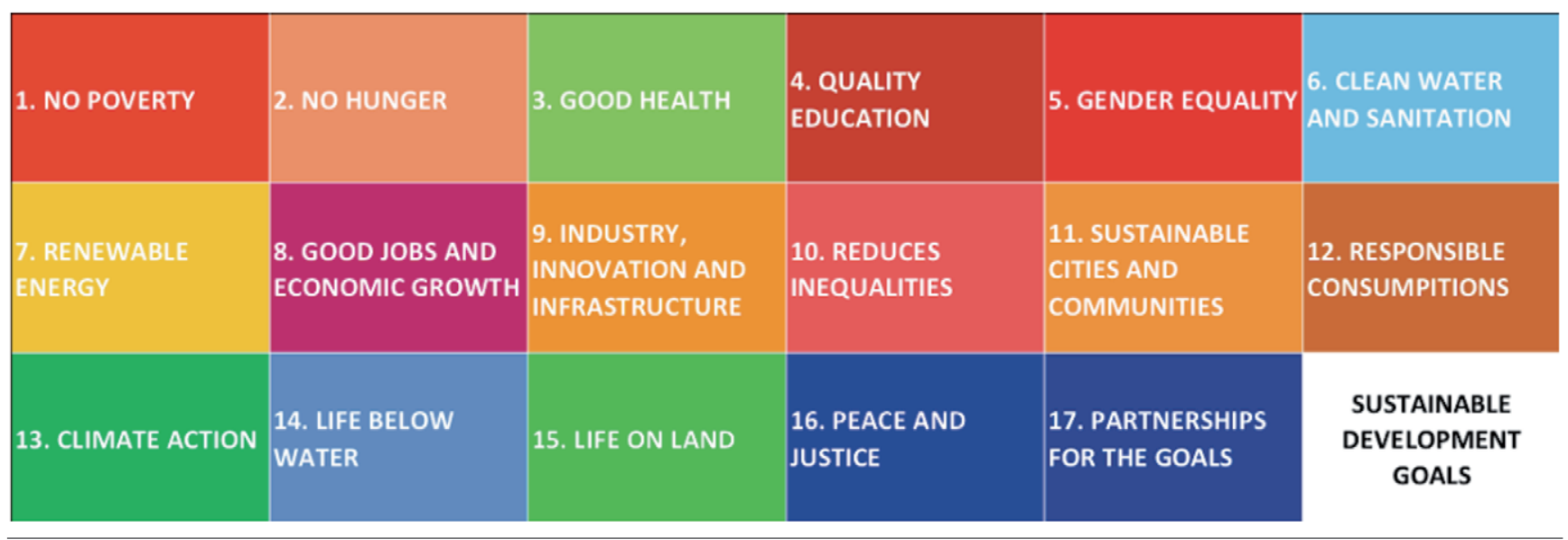

Figure 2. United Nations' Sustainable Development Goals (SDGs). 
tors, i.e., beds in residential facilities and Influenza vaccine coverage, the comparison with data from 2010 show a worsening.

On the contrary, for what concerns BES all the chosen indicators present an overall improvement. For those included in Health domain, for whom data from 2010 are available, a slightly decrease in mortality for dementia and nervous system diseases is

\begin{tabular}{|c|l|}
\hline Domain & \multicolumn{1}{|c|}{ Denomination } \\
\hline $\mathbf{1}$ & Health \\
\hline $\mathbf{2}$ & Education and Training \\
\hline $\mathbf{3}$ & Work and life balance \\
\hline $\mathbf{4}$ & Economic well-being \\
\hline $\mathbf{5}$ & Social relationships \\
\hline $\mathbf{6}$ & Politics and institutions \\
\hline $\mathbf{7}$ & Safety \\
\hline $\mathbf{8}$ & Landscape and cultural heritage \\
\hline $\mathbf{9}$ & Subjective well-being \\
\hline 10 & Environment \\
\hline 11 & Innovation, research and creativity \\
\hline 12 & Quality of services \\
\hline
\end{tabular}

Figure 3. Benessere Equo e Sostenibile (BES) Domains. observed, while life expectancy without activity limitations at 65 years of age ameliorates.

\section{A set of geriatric-related performance indicators to achieve international goals}

The following step is to understand how to improve, from a geriatric point of view, the Sustainability and Well-being indicators discussed above. A good practice for a Geriatric Unit might be the identification of a proper set of key performance indicators (KPIs), with the purpose to ameliorate general outcomes (BES and SDGs) through an improvement in performance. These KPIs should present two main requirements: i) they should be reported in the mandatory Performance Documents (such as Performance Plan and Performance Report) of the Local Health Agency (AUSL); ii) they should directly or indirectly connect to the improvement of SDGs or BES indicators. To the aim of this work, the case of an Italian region has been considered.
Emilia-Romagna Region (RER) has defined a set of indicators named 'Insid-ER' (Health Indicators and Dashboard - EmiliaRomagna) which is crucial to monitor the performance of every Local Health Agency in the regional network ${ }^{19}$ and to ensure comparability and transparency. These indicators are presented and described ex ante in the Performance Plan ('Piano della performance'), yearly published by each Local Health Agency of the RER, together with the baselines and the estimated values for the following years. Ex post, in Performance Report ('Relazione sulla performance') raw data should be illustrated.

Insid-ER is composed by 110 indicators divided in four dimensions: i) Users (41 indicators); ii) Internal Processes (56 Indicators); iii) Innovation and Development (4 indicators); iv) Sustainability (9 indicators). Each of this dimension is further divided in eight specific areas of interest.

To monitor the performance of Geriatric units, a subset of KPIs has been selected by Authors considering two criteria: i) reference to older age (65 years or more); ii) clinical or healthcare activities directly

Table 1. Geriatric-related indicators selected from Sustainable Development Goals (SDGs) and Benessere Equo e Sostenibile (BES) frameworks.

\begin{tabular}{lllll} 
Source & Goal & Id. & Indicator & \\
SDGs & \multirow{2}{*}{ Good Health and Well-being } & 3.8 .1 .3 & Hospital beds (per 10,000 inhabitants) & Pirection \\
& & 3.8 .1 .4 & Day-hospital beds in public and private care institutions (per 10,000 inhabitants) \\
& & 3.8 .1 .5 & Beds in the residential social-healthcare and social-welfare facilities (per 10,000 inhabitants) & Positive \\
& & $3 . b .1 .1$ & Influenza vaccination coverage age $65+$ (per 100 inhabitants) & Positive \\
BES & 1.6 & Age-standardized mortality rate for dementia and nervous system diseases (65 years and over) & Negative \\
& Health & 1.7 & Life expectancy without activity limitations at 65 years of age & Positive \\
& Quality of Services & 12.3 & Integrated home assistance service & Positive \\
\hline
\end{tabular}

Table 2. Key Performance Indicators for Geriatrics, connected to Transitional Care proposed as practical interventions on performance.

\begin{tabular}{|c|c|c|c|c|c|}
\hline Dimension & Area & n. & Indicator & Direction & Transitional Care \\
\hline \multirow[t]{4}{*}{ Users } & \multirow[t]{3}{*}{ Integration } & 1.1 & $\%$ of people $>=65$ years in integrated home assistance service & Positive & \multirow{4}{*}{$\begin{array}{l}\text { Outpatient local care; } \\
\text { clinical/nursing handover } \\
\text { Post-discharge follow-up } \\
\text { (home visits, ambulatorial } \\
\text { visits), hotline } \\
\text { Outpatient local care; } \\
\text { clinical/nursing handover }\end{array}$} \\
\hline & & 1.2 & $\begin{array}{l}\text { \% re-hospitalization within } 30 \text { days of discharge by Community } \\
\text { Hospital (OSCO) }\end{array}$ & Negative & \\
\hline & & 1.3 & $\begin{array}{l}\text { Rate of integrated home assistance service } x 1.000 \text { inhabitants, } \\
>=75 \text { years }\end{array}$ & Positive & \\
\hline & Outcome & 2.1 & Hip fracture surgery between two days from arrival (\%) & Positive & \\
\hline \multirow{7}{*}{$\begin{array}{l}\text { Internal } \\
\text { Processes }\end{array}$} & \multirow[t]{2}{*}{ Production-Hospital } & \multirow{2}{*}{$\begin{array}{l}3.1 \\
3.2\end{array}$} & \multirow{4}{*}{$\begin{array}{l}\text { Average Hospital Stay Index for acute medical hospitalization } \\
\% \text { of prolonged hospital stays for people aged } 65 \text { years and above } \\
\text { Average length of stay in Community Hospital (OSCO) } \\
\text { N. of specialist ambulatorial visits }\end{array}$} & \multirow{4}{*}{$\begin{array}{l}\text { Negative } \\
\text { Negative } \\
\text { Negative } \\
\text { Positive }\end{array}$} & Early discharge planning \\
\hline & & & & & \multirow{2}{*}{ Early discharge planning } \\
\hline & \multirow[t]{2}{*}{ Production-Local } & 4.1 & & & \\
\hline & & 4.2 & & & \\
\hline & Production-Prevention & 5.1 & Influenza vaccination coverage age $65+$ & Positive & Vaccine recommendation \\
\hline & $\begin{array}{l}\text { Appropriateness, } \\
\text { Quality, Safety and }\end{array}$ & 6.1 & $\begin{array}{l}\text { \% older people living in Residential facilities accessing } \\
\text { Emergency Department (ED) }\end{array}$ & Negative & $\begin{array}{l}\text { Residential or telephone } \\
\text { consultations }\end{array}$ \\
\hline & Clinical Risk & 6.2 & $\begin{array}{l}\% \text { older people living in Residential facilities with re-hospitalization } \\
\text { within } 30 \text { days }\end{array}$ & Negative & $\begin{array}{l}\text { Post-discharge follow-up } \\
\text { (home visits, ambulatorial } \\
\text { visits), hotline }\end{array}$ \\
\hline
\end{tabular}


related to Geriatrics. By this analysis, eleven indicators are shown in Table 2, where the dimension, the area, the name of indicator and the direction are included for each KPI.

In Dimension 'Users', two Areas present KPIs of geriatric interest. In Integration area, a focus is made on integrated home assistance service with a direct claim on older age. The issue is considered in terms of percentage of users for people with 65 years and above and as a rate over 1000 inhabitants for people with 75 years and above. Moreover, the percentage of re-hospitalization within 30 days of discharge from Community Hospital is concerned. In Outcome area, hip fracture patients are considered and the objective is to ensure the early execution of orthopedic surgery. The population in question frequently consists of elderly and frail persons. In this sense, Orthogeriatrics provides an effective methodology for the global evaluation of the patients in order to minimize pre- and post-surgical complications. ${ }^{20}$

In Dimension 'Internal Processes', the Production area is distinguished in three levels. Regarding Hospital level, attention is kept on length of stay in terms of average hospital stay index and as percentage of prolonged hospital stays for patients with 65 years or more. At local level, length of stay is considered in Community hospital stays. Moreover, this Dimension contains the amount of specialist visits in ambulatorial settings. At Prevention level, Influenza vaccination coverage for elderly is considered. Finally, in 'Appropriateness, Quality, Safety and Clinical Risk' Dimension, the target population is represented by older people living in residential facilities, whose accesses to ED and re-hospitalizations within 30 days of discharge are monitored.

To build a novel framework, all the KPIs described above can potentially contribute to the improvement of SDGs and BES. Nonetheless, it is possible to remark some direct and straightforward relationships, summarized in the following: i) influenza vaccination coverage age $65+\rightarrow$ SDG 3.b.1.1; ii) $\%$ of people $\geq 65$ years in integrated home assistance service $\rightarrow$ BES 12.3; iii) rate of integrated home assistance service $\times 1000$ inhabitants, $\geq 75$ years $\rightarrow$ BES 12.3.

In these cases, it is not difficult to assume that an improvement in KPIs of all the health actors in a given region (such as the RER) would produce an improvement on the related BES/SDG, almost at regional level. For instance, an improvement in 'Influenza vaccination coverage age 65+' among the hospital network in RER would produce an improvement of the indicator 3.b.1.1, almost for RER itself, remarking that the two indicators share a positive direction.

Thus, other interactions between selected KPIs and BES/SDGs can be hypothesized. As an example, the abovementioned contraction in hospital beds availability at a national and regional level, as measured through SDGs, needs a focus on hospital length of stays and re-hospitalizations. An accurate usage of the disposable resources, in a logic of appropriateness and prudent efficiency, would undoubtedly result beneficial.

These topics are crucial in Geriatrics, as frail and older people are ED frequent-user and often hospitalized longer.

\section{Transitional care interventions to improve KPIs in Geriatrics}

The ultimate purpose of this work is to define how Geriatric methodology can provide an effective impact on KPIs and, consequently, on BES/SDGs. This reflection is not merely related to patients' age, but it is specifically connected to the approach to the patient typical of Geriatrics.

In Table 2, the last column synthetizes actions and procedures which fall within the scope of Transitional Care (TC). These are interventions adopted to supervise the transition between different healthcare settings (e.g. hospital to home, ambulatorial to local health center) in order to ensure the continuity of care and to avoid the loss of information (e.g. new diagnosis, new therapies) through healthcare settings. As older patients are those more vulnerable and more frequently subject to the transition from one setting to another, ${ }^{21} \mathrm{TC}$ interventions should be of daily use in Geriatrics. In fact, they can represent practical (and potentially lowcost) solutions to inappropriate prolongation of hospitalizations, re-hospitalizations and ED accesses. ${ }^{22}$

Early discharge planning consists in the construction of a project of discharge started as soon as the patient is admitted in hospital. Its timeliness is responsible of the efficiency of the recovery, while minimalizing the possibility of complications and the probability of re-hospitalization. Its success depends on multidisciplinary asset, patienttailored perspective and liaising with health and social services in primary healthcare. ${ }^{23}$ It goes without saying that early discharge planning might be beneficial for those KPIs related to length of stay (in both Hospitals and Community Hospitals), with the aim to reduce the inappropriate prolongation of hospitalization. Anyway, the efficacy of the discharge planning realization is also dependent on adequacy and wealth of the local primary health centers (in RER 'Case della Salute'), which are responsible for outpatient local care. In this context, the integrated home assistance service is crucial for non-autonomous, vulnerable patients with generic (hygienic care, meal deliveries) or specific care needs (medications, bladder catheter management, home blood draws for anticoagulation therapy). Geriatric evaluation assumes a prominent role in this assessment for the individuation of each patient's weaknesses and necessities and, as a response, for the production of a patient-tailored project. Yet, the interconnection between hospital and local/home setting is promoted through clinical and nursing handover, which is crucial for the implementation of the project itself. In this context, General Practitioners have to be allies in the patient care process.

Moreover, with the aim to favor the continuity of care and, contemporarily, to reduce ED accesses and re-hospitalizations, post-discharge follow-ups might be relevant solutions both for home-living and residential patients. These can be considered as nursing or medical visits in different settings, such as ambulatorial or home. In addition, a hotline may be identified, with the aim to provide patients a direct line with referring healthcare professionals. Finally, especially for older patients living in residential facilities, telephone or in-person consultations may be useful to avoid improper accesses to ED.

\section{Concluding Remarks}

After a one year since the outbreak of COVID-19 pandemic, in Italy geriatric population has been the most affected in terms of mortality ${ }^{24}$ and morbidity, amplifying issues related to social intergenerational equity and healthcare institutions' organization.

This work focuses on the possible linkages between Sustainable Development and Well-being indicators and performance indicators from a Geriatric point of view, discussing some reflections and solutions useful to propose a novel framework. In particular, it is discussed whether improving geriatric performance, measured through a set of validated KPIs, can have a concrete role to ameliorate (or keep stable) SDGs and BES indicators. At the local level, Transitional Care could be considered among the main determinants of performance in Geriatrics, and this relationship will be investigated through further quantitative and qualitative methodologies. 
Moreover, the role of Geriatrics to achieve national and international goals is expected to become increasingly important. For instance, it is known that Domain 1 of BES ('Health') will be enriched by a new indicator regarding the percentage of people over 75 with multi-chronicity or severe limitations. ${ }^{25}$ In this sense, further studies will regard the definition of a proper and shared set of performance indicators for geriatric units. Thus, quantitative studies will help to evaluate and/or measure the real impact of performance indicators on SDGs and BES, at regional and national level.

\section{References}

1. ISTAT. Indicatori Demografici anno 2019 Report; 2020. Available from: http://demo.istat.it

2. Crimmins EM, Beltrán-Sánchez $H$. Mortality and morbidity trends: is there compression of morbidity? J Gerontol B Psychol Sci Soc Sci 2011;66:75-86.

3. George G, Jell C, Todd BS. Effect of population ageing on emergency department speed and efficiency: a historical perspective from a district general hospital in the UK. Emerg Med J 2006;23:379-83.

4. Partridge JS, Collingridge G, Gordon $\mathrm{AL}$, et al. Where are we in perioperative medicine for older surgical patients? A UK survey of geriatric medicine delivered services in surgery. Age Ageing 2014;43:721-4.

5. Bo M, Fonte G, Pivaro F et al. Prevalence of and factors associated with prolonged length of stay in older hospitalized medical patients. Geriatr Gerontol Int 2016;16:314-321.

6. Carpentieri G, Guida C, Masoumi HE. Multimodal accessibility to primary health services for the elderly: A case study of Naples, Italy. Sustainability 2020;12:781.

7. Marchetti G, Simonelli M, Dente MG et al. Accessibility to health services in Italy and in the world. Eur J Public Health, 2020;30:ckaa166-1398.

8. United Nations. Sustainable Development. Available from: http://sdgs.un.org

9. Murray CJ. Shifting to Sustainable Development Goals - implications for global health. New Engl J Med 2015;373:1390-3.

10. Hogan DR, Stevens GA, Hosseinpoor AR, Boerma T. Monitoring universal health coverage within the Sustainable Development Goals: development and baseline data for an index of essential health services. Lancet Glob Health, 2018;6:e152-68.

11. Fullman N, Barber RM, Abajobir AA, et al. Measuring progress and projecting attainment on the basis of past trends of the health-related Sustainable Develop-ment Goals in 188 countries: an analysis from the Global Burden of Disease Study 2016. Lancet, 2017;390:1423-59.

12. United Nations. Measuring progress towards the SDGs. Available from: http://sdg-tracker.org

13. ISTAT. Rapporto Sdgs 2020. Informazioni Statistiche Per L'agenda 2030 In Italia. Available from: https:/www.istat.it/it/ files//2020/05/SDGs_2020.pdf

14. ASviS. Rapporto ASviS 2020. I territori e gli Obiettivi di Sviluppo sostenibile. Available from: https://asvis.it/public/ asvis2/files/Pubblicazioni/RAPPORTO_ASviS_TERRITORI_2020.pdf

15. Alaimo L $\bar{S}$, Maggino $\bar{F}$. Sustainable development goals indicators at territorial level: Conceptual and methodological issues - The Italian perspective. Soc Indic Res 2020;147:383-419.

16. ISTAT. BES 2019. Il Benessere Equo e Sostenibile in Italia. Available from:
https://www.istat.it/it/files//2019/12/Be s_2019.pdf

17. Bacchini F, Baldazzi B, Di Biagio L. The evolution of composite indices of well-being: An application to Italy. Ecol Indic 2020;117:106603.

18. ISTAT. Le differenze territoriali di benessere. Una lettura a livello provinciale; 2019. Available from: https:// www.istat.it/it/files//2019/09/Differenz e-territoriali.pdf

19. Papi L, Ievoli R, Gobbo G, et al. Performance governance per la generazione di Valore Pubblico in sanità. Evidenze empiriche dalle aziende sanitarie dell'Emilia-Romagna. Mecosan 2021;117:27-58.

20. Zurlo A, Bellelli G. Orthogeriatrics in Italy: the Gruppo Italiano di Ortogeriatria (GIOG) audit on hip fractures in the elderly. Geriatric Care 2018;4:7726.

21. Coleman EA, Boult C. Improving the quality of transitional care for persons with complex care needs: Position statement of the American Geriatrics Society Health Care Systems Committee. J Am Ger Soc 2003;51:556-7.

22. Pines JM, Mullins PM, Cooper JK, et al. National trends in emergency department use, care patterns, and quality of care of older adults in the United States. J Am Ger Soc 2013;61:12-7.

23. Gonçalves-Bradley DC, Lannin NA, Clemson LM et al. Discharge planning from hospital. Cochrane Database Syst Rev 2016;1.

24. ISTAT-ISS. Impatto dell'epidemia COVID-19 sulla mortalità totale della popolazione residente; 2021 Available from: https://www.istat.it/it/files//2021 /03/Report_ISS_Istat_2020_5_marzo.pdf

25. ISTAT. BES 2020. Il Benessere Equo e Sostenibile in Italia. Available from: https://www.istat.it/it/files//2021/03/BE S_2020.pdf 